Original article

\title{
DETECTION OF MYCOBACTERIUM AVIUM SUBSP. PARATUBERCULOSIS IN AN EGYPTIAN MIXED BREEDING FARM AND COMPARATIVE MOLECULAR CHARACTERISATION OF ISOLATES FROM CATTLE, CAMELS AND CATS - A CASE REPORT
}

\author{
M. SALEM ${ }^{1,2,3}$, W. EL-DEEB ${ }^{2,4}$, K. ABDEL-MOEIN ${ }^{5}$, A. EL-SAYED $^{1}$, \\ A. FAYED ${ }^{1}$, F. HOUSAWI ${ }^{2}$, A. AL-NAEEM ${ }^{2} \&$ M. ZSCHÖCK ${ }^{6}$ \\ ${ }^{1}$ Department of Medicine and Infectious Diseases, Faculty of Veterinary Medicine, Cairo \\ University, Egypt; ${ }^{2}$ Department of Clinical Studies. College of Veterinary Medicine, King \\ Faisal University, Kingdom of Saudi Arabia; ${ }^{3}$ King Faisal University, Veterinary Teaching \\ Hospital, Kingdom of Saudi Arabia; ${ }^{4}$ Department of Veterinary Medicine, Infectious Dis- \\ eases and Fish Diseases, Faculty of Veterinary Medicine, Mansoura University, Mansoura, \\ Egypt; ${ }^{5}$ Department of Zoonosis, Faculty of Veterinary Medicine, Cairo University, Egypt; \\ ${ }^{6}$ Department of Veterinary Medicine, Hessen State Laboratory, Giessen, Germany
}

\section{Summary}

Salem, M., W. El-Deeb, K. Abdel-Moein, A. El-Sayed, A. Fayed, F. Housawi, A. AlNaeem \& M. Zschöck, 2019. Detection of Mycobacterium avium subsp. paratuberculosis in an Egyptian mixed breeding farm and comparative molecular characterisation of isolates from cattle, camels and cats - a case report. Bulg. J. Vet. Med., 22, No 1, 41-49.

\begin{abstract}
The present study records and investigates an outbreak of Johne's Disease in a mixed breeding camel - cattle farm and the possible role of non-domestic non-ruminants animals in the epidemiology of Mycobacterium avium subspecies paratuberculosis in Egypt. For this reason, faecal samples were collected from 24 dairy cattle and from 15 one humped Arabian camels suffering from diarrhoea. Moreover, intestinal tissue samples were provided from 7 cats and 2 rats that were caught from the same farm and were euthanized before necropsy. Samples were examined using traditional culture and IS900 PCR techniques together with the application of BstEII-IS900 RFLP for typing of obtained isolates. Interestingly, MAP was recovered from cattle $(n=8)$ and from camels $(n=3)$ and nondomestic cats $(n=3)$ reared under local conditions in this farm in Egypt. The obtained results highlight the potential role of cats in the epidemiology of MAP, a subject which needs further investigation and might have a public health importance, catsbeing common members of many families.
\end{abstract}

Key words: camels; Egypt, Johne's disease; MAP; non-domestic non-ruminant animals

\section{INTRODUCTION}

Since 1895 when Mycobacterium avium subspecies paratuberculosis (MAP) was brought to light, the importance of this organism has steadily increased to become 
Detection of Mycobacterium avium subsp. paratuberculosis in an Egyptian mixed breeding farm ....

a great challenge in veterinary medicine (Salem et al., 2013). MAP is the causative agent of Johne's disease (JD), a fatal chronic enteritis leading to massive economic losses to the ruminant industry (Bryant et al., 2016). Domestic and wild ruminants are the main natural reservoirs for MAP including cattle, sheep, goats and deer. However, the organism showed the ability to jump the species barrier to expand its host range as it was found in other non-ruminant animals including some wild reservoirs such as foxes, weasels, rats and boars (Kim et al., 2013). Moreover, MAP was isolated from diseased persons with inflammatory bowel syndrome (Crohn's disease) a matter of great interest suggesting a zoonotic potential of this Mycobacterium species (Scanu et al., 2007).

The disease in ruminants is characterised by a prolonged subclinical stage then appear signs as loss of condition, decrease in milk yield, weight loss and diarrhoea which may be intermittent first then becomes constant, more severe, not responsive to antibiotic treatment and finally the animal dies (Salem et al., 2013; El-Deeb et al., 2014). Johne's disease was reported worldwide while in Egypt it was largely ignored for several years as it was thought that Egypt was free from JD. This concept was mostly believed until broken by Salem et al. (2005) who isolated MAP from diseased cattle from three different Egyptian districts denoting the existence of the disease in Egypt.

The present study records and investigates an outbreak of JD in a mixed breeding camel-cattle farm and the possible role of non-domestic non-ruminant animals in the epidemiology of MAP in Egypt.

\section{MATERIALS AND METHODS}

\section{Samples}

Faecal samples were collected from 24 dairy cattle (Holstein-Friesian) and from 15 one humped Arabian camel (Camelus dromedaries) in a mixed breeding camelcattle farm in Sinai Peninsula. These animals showed various degree of diarrhoea from severe, non-responsive to antibiotic treatment, to chronic or intermittent. In addition, faeces and tissue samples (intestinal sections, ileocaecal junction and intestinal lymph nodes) were collected from 7 cats and 2 rats that were caught at the same farm and were euthanised before necropsy. Briefly, animals were anesthetised with a mixture of ketamine and xylazine at recommended dosages and were euthanised by intracardiac injection of sodium pentobarbital and transported to the laboratory immediately (Palmer et al., 2005).

All samples were sent to the laboratory in ice box with minimum delay. Up on arrival, faecal and tissue samples were decontaminated as previously described (Palmer et al., 2005; Salem et al., 2005). Samples were processed in 2 parallel directions comprising direct detection of MAP in the samples by IS900 PCR and bacterial isolation and identification followed by characterisation by IS900RFLP.

Direct detection of MAP in faecal and tissue samples by IS900 PCR assay

Firstly, DNA was extracted from faecal samples by using DNA extraction stool mini kit and the procedure was carried out with slight modifications of the directions of the manufacturer (Qiagen). DNA from tissue samples was extracted according to the method described by Bull et al., (2003). 


\section{IS900 PCR}

This assay was carried out according to Bull et al. (2003). Briefly, $5 \mu \mathrm{L}$ of the extracted DNA from the samples was used in a final reaction volume of $50 \mu \mathrm{L}$ with 2 $\mu \mathrm{M}$ of each primers TJ1 (5' GCT GAT CGC CTT GCT CAT 3'), TJ2 (5' CGG GAG TTT GGT AGC CAG TA 3'). Thermal profile was 1 cycle of $94^{\circ} \mathrm{C}$ for 5 min and then 30 cycles of $94^{\circ} \mathrm{C}$ for $1 \mathrm{~min}$, $60{ }^{\circ} \mathrm{C}$ for $1 \mathrm{~min}$, and $72{ }^{\circ} \mathrm{C}$ for $3 \mathrm{~min}$, then one cycle of $72{ }^{\circ} \mathrm{C}$ for $7 \mathrm{~min}$. A positive control (DNA from the ATCC 19698 strain) and a negative control (sterile bidistilled water) were included in each PCR run. Specific bands were visualized with ethidium bromide on $1.5 \%$ agarose gels.

\section{Isolation of MAP from faecal and tissue samples}

Samples were decontaminated and cultured on 3 HEYM slants supplied with mycobactin $\mathrm{J}$ and 1 HEYM slant without mycobactin $\mathrm{J}$ (Becton Dickinson). After incubation at $37{ }^{\circ} \mathrm{C}$ for 40 weeks, cultures with visible growth were further processed to identify MAP primarily on the basis of colonial characters, acid fastness and mycobactin $\mathbf{J}$ growth dependence (Salem et al., 2013).

\section{Molecular identification of isolates}

DNA was obtained from visible colonies by direct bacterial boiling at $100{ }^{\circ} \mathrm{C}$ for 10 minutes and was used for 2 specific PCR assays, an IS900 PCR and amplification of the locus 251. The procedure of IS900 PCR was the same as mentioned above. While sequence 251 was amplified using the forward primer 5-CAC GTG CTG TCC CCA TCG GC-3 and the reverse 5CTA CGT CTT CGT GAC CAA AG-3 (Bannantine et al., 2002).

\section{Isolation of genomic DNA from isolates}

Colonies were sub cultured on middle brook $7 \mathrm{H} 9$ broth supplied with $0.05 \%$ tween 80 (Difco), 10\% oleic acid - albumin dextrose catalase (OADC) enrichment (Becton Dickinson) and 2 micrograms $/ \mathrm{ml}$ of Mycobactin J (Synbiotics). Isolates were incubated at $37^{\circ} \mathrm{C}$ for at least 6 weeks before the isolation of genomic DNA. Bacterial cells were harvested at least in the log phase of growth $\left(\mathrm{A}_{540}=\right.$ $0.4)$. DNA was obtained by the standard cetyltrimethylammonium bromide (CTAB) method (Pavlik et al., 1999). DNA yields were then calculated based on the optical density measurement at $260 \mathrm{~nm}$ on a Nanodrop-spectrophotometer.

\section{IS900 RFLP}

The assay was conducted according to (Salem 2009). Briefly, from each strain, approximately $2 \mu \mathrm{g}$ purified DNA were digested with restriction endonuclease BstE II following the conditions provided by the manufacturer (Fermentas). DNA fragments were separated after electrophoresis carried out in $1 \%$ agarose gels at $55 \mathrm{~V}$ for $17 \mathrm{~h}$ and were transferred onto positively charged nylon membrane (Roche diagnostics) using standard capillary blotting procedures (Salem, 2009). Hybridization took place for $16 \mathrm{~h}$ at $42^{\circ} \mathrm{C}$ with freshly prepared hybridisation buffer containing a Digoxigenin (Roche diagnostics) labelled DNA probe prepared by PCR amplification of MAP, ATCC 19698 (K-10) strain using a primer set derived from positions 209 and 662 of the insertion sequence 900 (forward MS1: 5'-TGG ACA ATG ACG GTT ACG GAG GTG G-3', reverse MS2: 5'-GAT CGG AAC GTC GGC TGG TCA GGA T-3'). DIGDNA hybrids were visualized by autoluminography with DIG luminescent detec- 
tion kit as recommended by the manufacturer (Roche diagnostics).

\section{Animal rights statement}

The producer was informed about the utilisation of animals and samples during this investigation, consent was obtained, and the investigation adhered to a high standard of veterinary care and ethics.

\section{RESULTS}

Eight MAP isolates were recovered from investigated cattle samples giving an isolation rate of $33.3 \%$, while 14 cows $(58.3 \%)$ were identified by PCR. Three camels yielded MAP in their faces by culture method, whereas MAP was recovered in 5 animals only by PCR. Furthermore, out of 7 examined cats, 3 were positive with both culture and PCR while none of the examined rats was positive (Table 1). MAP was cultured and/or detected from different parts of intestinal tissues as well as intestinal lymph nodes from positive cats (Table 2). All isolates were con- firmed to be MAP by using both IS900 PCR and amplification of the locus 251 .

In the current study, all isolates were genotyped by IS900-BstEII RFLP. Fig. 1 shows all obtained patterns when compared to those from previous reports. We have taken the $\mathrm{C} 1$ type as the reference profile and defined other profiles by listing additional or deleted individual bands using red bands and red arrowheads respectively, which correspond to the number and size of each band in $\mathrm{kb}$. The segregation of MAP isolates with BstEIIIS900 RFLP from 3 hosts highlighted similarities and differences in the prevalence and diversity of obtained types. A total of 3 types were perceived after fingerprinting 14 MAP isolates (cattle $n=8$, camel $n=3$, cat $n=3$ ).

\section{DISCUSSION}

Paratuberculosis is considered as a significant problem in the veterinary field and critical threat to the livestock industry worldwide with a mounting public health

Table 1. Animal species, PCR results, culture resuts and IS900-BstE II RFLP profiles.

\begin{tabular}{|c|c|c|c|c|c|}
\hline $\begin{array}{l}\text { Animal } \\
\text { species }\end{array}$ & $\begin{array}{l}\text { IS900 PCR } \\
\text { positive } \\
\text { number (\%) }\end{array}$ & $\begin{array}{c}\text { Culture } \\
\text { positive } \\
\text { number (\%) }\end{array}$ & $\begin{array}{l}\text { Colonial } \\
\text { characteristics }\end{array}$ & $\begin{array}{c}\text { IS900 \& } \\
\text { L. } 251 \\
\text { culture } \\
\text { positive }\end{array}$ & $\begin{array}{l}\text { IS900- BstE } \\
\text { II RFLP } \\
\text { profile** }\end{array}$ \\
\hline $\begin{array}{l}\text { Cattle } \\
(\mathrm{n}=24)\end{array}$ & $\begin{array}{c}14 \\
(58.3 \%)\end{array}$ & $\begin{array}{c}8 \\
(33.3 \%)\end{array}$ & $\begin{array}{l}\text { Fast growers } \\
\text { AFB* } \\
\text { (6-8 weeks) }\end{array}$ & 8 & $\mathrm{C} 18$ \\
\hline $\begin{array}{l}\text { Camels } \\
(\mathrm{n}=15)\end{array}$ & $\begin{array}{c}5 \\
(33.3 \%)\end{array}$ & $\begin{array}{c}3 \\
(20 \%)\end{array}$ & $\begin{array}{l}\text { Slow growers } \\
\text { AFB } \\
\text { (14-16 weeks) }\end{array}$ & 3 & CS (new) \\
\hline $\begin{array}{l}\text { Cats } \\
(n=7)\end{array}$ & $\begin{array}{c}3 \\
(42.8 \%)\end{array}$ & $\begin{array}{c}3 \\
(42.8 \%)\end{array}$ & $\begin{array}{l}\text { Fast growers AFB } \\
\text { (6-9 weeks) }\end{array}$ & 3 & $\mathrm{C} 1$ \\
\hline $\begin{array}{l}\text { Rats } \\
(\mathrm{n}=2)\end{array}$ & - & - & - & - & - \\
\hline
\end{tabular}

* AFB: acid fast bacilli; ** According to Pavlik et al. (1999). 
M. Salem, W. El-Deeb, K. Abdel-Moein, A. El-Sayed, A. Fayed, F. Housawi, A. Al-Naeem \& M. Zschöck

Table 2. Detection of MAP in faeces and tissues of tested cats by IS900 PCR and culture methods

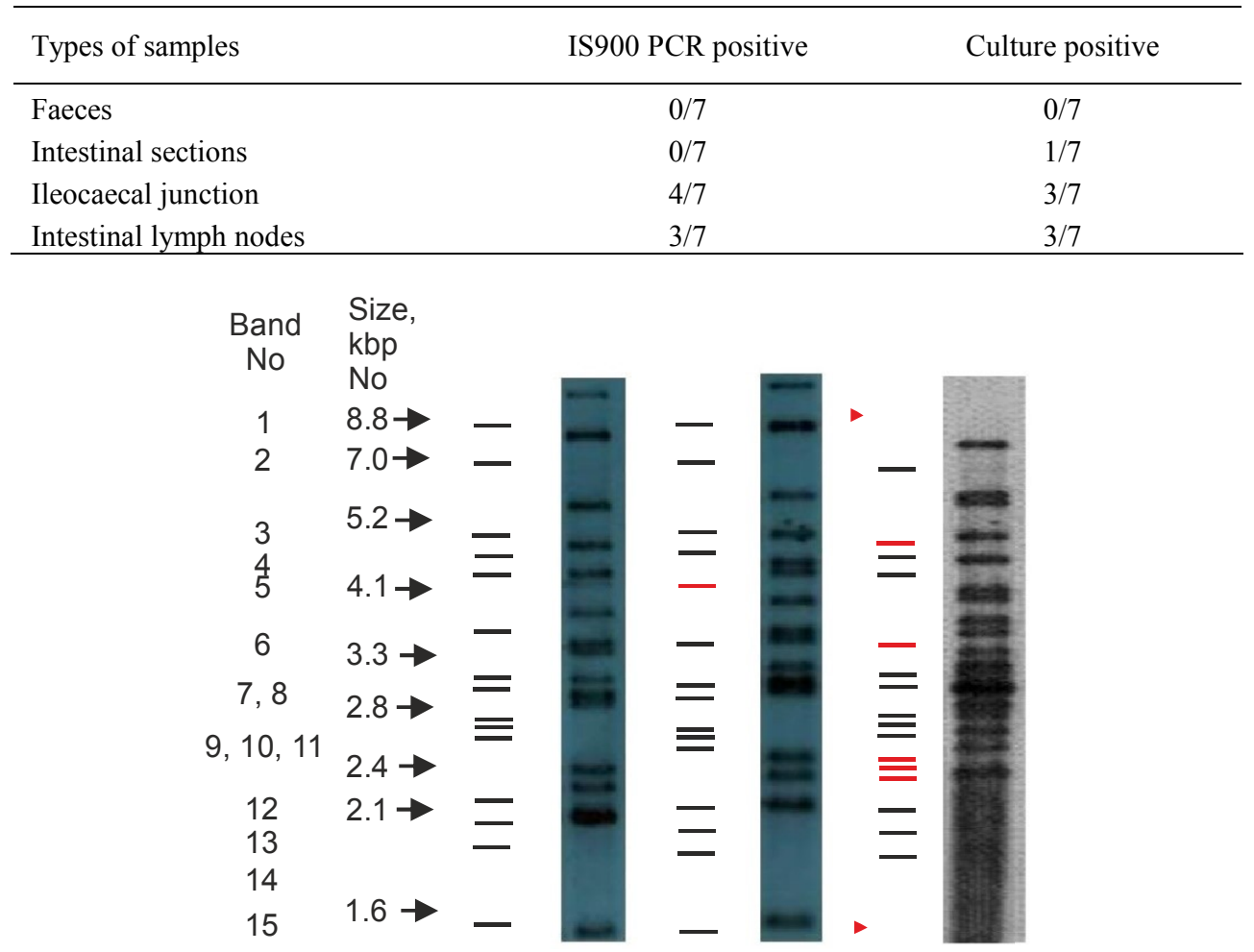

Fig 1. RFLP IS900 BstEII patterns: the $\mathrm{C} 1$ type is taken as reference profile and other profiles were defined by listing additional individual bands (in red): one additional band in C18 profile and 5 in the CS profile. Deleted bands are indicated with red arrowheads (two deleted bands in the CS profile). The number and size of each band in kbp are according to Pavlik et al. (1999)

concern (Collins, 2003). The results of the current study revealed an outbreak of paratuberculosis in a dairy cattle farm in Sinai. The outbreak involved 24 dairy cattle and 15 camels (Table 1) that showed a various degree of diarrhoea ranged from severe profuse diarrhoea which did not respond to antibiotic treatment to mild intermittent accompanied by loss of condition and decrease in milk yield. MAP was recovered from 8 cows with a recovery rate of $33.3 \%$, whereas the organism was cultured from the feces of 3 out of 15 camels with a ratio of $20 \%$. PCR was able to identify 14 cattle
$(58.3 \%)$ and 5 camels $(33.3 \%)$ denoting that both diseased and infected animals shed the organism in their faeces to be a source of infection for other animals and thereby exaggerate (complicate) the situation in the farm thus appearance of new cases might be seen later on (Salem et al., 2012).

Interestingly, we investigated the occurrence of MAP among cats and rodents that lived in the affected farm during this outbreak to explore the probable role of these animals in the epidemiology of paratuberculosis (Table 1) and surprisingly, the obtained results displayed a 
high unexpected prevalence of MAP infection in cats $(42.8 \%)$ and the organism was isolated from intestines and intestinal lymph nodes of the infected cats pointing out a true infection (Table 2). This result is supported by the findings of Corn et al., (2005) who documented natural infection of cats by MAP ( 2 out of 18 with a ratio $11.1 \%$ ) and recovered MAP from the faeces of an infected cat during a survey to prove a faecal shedding of MAP by cats; however we could not detect it in the faeces of examined cats.

Therefore, cats assumed to be an important non ruminant reservoir for MAP and may be incriminated in the dissemination of MAP among different yards in the farm. It is noteworthy that the home range of the free living cats may extend to include more than one farm and so they are able to introduce the infection to other farms specially MAP free ones (Daniels et al., 2003). Moreover, the public health importance of our findings extends beyond the role of cats in the transmission of MAP between animals because the zoonotic potential of MAP could not be ignored. MAP is a strong candidate for Chron's disease in humans and the organism was cultured and verified from many cases and even from the ileocolonic mucosal biopsies from patients with Chron's disease (Bull et al., 2003; Sechi et al., 2005). Meanwhile, both molecular and epidemiological evidence were achieved to correlate MAP to be a cause of Chron's disease (Clancy et al., 2007; Uzoigwe et al., 2007).

In the present study all fast growers recovered from cattle clustered in the $\mathrm{C} 18$ type, while those isolates recovered from cats clustered in the $\mathrm{C} 1$ type. On the other hand all slow growers (camel isolates) clustered in a separate new type that was named CS type (Fig 1). Bovine isolates from Sinai Peninsula clustered in the C18, which is a type also known to infect cattle in Europe (Pavlik et al., 1999). None of these bovine isolates clustered in the $\mathrm{C} 1$ type in the contrary to feline isolates. The $\mathrm{C} 1$ is a type known to infect a wide range of hosts including ruminants, non-ruminants and non human primates (Pavlik et al., 1999). The $\mathrm{C} 1$ type was previously described to be the only type detected among 15 Egyptian cattle isolates from 3 Governorates namely Ismailia, Menoufia and Cairo, and it was then related to the process of cattle importation in the last century from different countries in Europe and USA where the $\mathrm{C} 1$ is the dominant type among cattle (unpublished data). On the other hand all camel isolates clustered in a separate new type related to the sheep strains suggesting that camels could have acquired the infection from sheep since they both share the same pasture.

The epidemiology of MAP was viewed from different angles. About the zoonotic perspective, many authors have concluded that MAP infected humans and the MAP human isolates had the same genetic fingerprints of those recovered from animals (Feller et al., 2007; Abubakar et al., 2008). Furthermore, the epidemiology of MAP in humans is not wellknown however it is most likely that humans are exposed to MAP through ingestion of contaminated food, especially milk (Grant et al., 2002; Ellingson et al., 2005). Moreover, human infection also may be attributed to contact with infected animals as high MAP prevalence was recorded in animal attendants who work with JD infected herds (Singh et al., 2008; 2011). In this regard, the isolation of MAP from cats highlighted the possible zoonotic transmission from cats to man. Cats are considered as common pet ani- 
mals in households, kept in intimate contact with their owners.

So, infected cats can bring MAP to your house to contaminate the household environment as well as your food with this robust harmful bacterium. Special attention should be paid for children as in the last few years there is a growing increase in the incidence of pediatric Chron's disease while MAP was isolated from the gut tissues and blood from children with Chron's disease (Kirkwood et al., 2009; Wagner et al., 2011). Also, MAP was implicated in autism in children, which may complicate MAP infections in children (Daw 2011). So, MAP may constitute a big hazard for children and when this bacterium was recovered from cats this magnifies the hazard for the children who usually enjoy fondling their pets. It should be mentioned that the $\mathrm{C} 1$ genotype which was isolated from the cats in our study was previously cultured from patients with Chron's disease (Whittington et al., 2000). Unfortunately, the number of rats that were caught from the farm was too small to build up any conclusion about the role, which could be played by rodents in the epidemiology of MAP during this outbreak.

\section{CONCLUSION}

In conclusion, this outbreak confirmed the spread of Johne's disease in Egypt and pointed out that the disease might be passed undiagnosed in many farms due to lack of information or diagnostic facilities. On the other hand, the high prevalence of MAP in cats magnified the possible role of cats in the epidemiology of MAP and highlighted the ability of these animals to convey MAP to both animals and humans outside the farm environment whereas the role of rodents in the epide- miology of MAP needs further research. In addition, further investigation of the epidemiology of MAP in unstudied species like camel would be a unique contribution to the global picture of MAP epidemiology. In spite of the high genetic conservation among the MAP population, the occurrence of multiple genotypes within the same farm highlights the old hypothesis that multiple clones of MAP might be responsible for a single infection within a single herd or a single yard and even within individual animals. It remains a speculation and warrants further studies whether these types are types transmitted to this farm through an unknown source of infection or were formed as a consequence of a genetic mutation of an already existing type to make a sort of adaptation to a new host species or to the development of clinical and/or sub clinical disease. Thus, special efforts should be implemented to control MAP and its veterinary and public health implications considering the zoonotic aspect of MAP cannot be ruled out.

\section{ACKNOWLEDGEMENTS}

This study was supported, in part, by a grant from the Science and Technology Development Foundation (STDF), Egypt and from the private farm under investigation.

\section{REFERENCES}

Abubakar, I., D. Myhill, S. H. Aliyu \& P. R. Hunter, 2008. Detection of Mycobacterium avium subspecies paratuberculosis from patients with Crohn's disease using nucleic acid-based techniques: a systematic review and meta-analysis. Inflammatory Bowel Diseases, 14, 401-410.

Bannantine, J. P., E. Baechler, Q. Zhang, L. Li \& V. Kapur, 2002. Genome scale comparison of Mycobacterium avium subsp. 
Detection of Mycobacterium avium subsp. paratuberculosis in an Egyptian mixed breeding farm ....

paratuberculosis with Mycobacterium avium subsp. avium reveals potential diagnostic sequences. Journal of Clinical Microbiology, 40, 1303-1310.

Bryant, J. M., V. C. Thibault, D. G. Smith, J. McLuckie, I. Heron, I. A. Sevilla, F. Biet, S. R. Harris, D. J. Maskell, S. D. Bentley, J. Parkhill \& K. Stevenson, 2016. Phylogenomic exploration of the relationships between strains of Mycobacterium avium subspecies paratuberculosis. BMC Genomics, doi: 10.1186/s12864-015-2234-5.

Bull, T. J., E. J. McMinn, K. Sidi-Boumedine, A. Skull, D. Durkin, P. Neild, G. Rhodes, R. Pickup \& J. Hermon-Taylor, 2003. Detection and verification of Mycobacterium avium subsp. paratuberculosis in fresh ileocolonic mucosal biopsy specimens from individuals with and without Crohn's disease. Journal of Clinical Microbiology, 41, 2915-2923.

Clancy, R., Z. Ren, J. Turton, G. Pang \& A. Wettstein, 2007. Molecular evidence for Mycobacterium avium subspecies paratuberculosis (MAP) in Crohn's disease correlates with enhanced TNF-alpha secretion. Digestive and Liver Disease, 39, 445-451.

Collins, M. T., 2003. Paratuberculosis: Review of the present knowledge. Acta Veterinaria Scandinavica, 44, 217-221.

Corn, J. L., E. J. B. Manning, S. Streevatsan \& J. R. Fischer, 2005. Isolation of Mycobacterium avium subsp. paratuberculosis from free-ranging birds and mammals on livestock premises. Applied and Environmental Microbiology, 71, 6963-6967.

Daniels, M. J., M. R. Hutchings, P. M. Beard, D. Henderson, A. Greig, K. Stevenson \& J. M. Sharp., 2003. Do non-ruminant wildlife pose a risk of paratuberculosis to domestic livestock and vice versa in Scotland? Journal of Wildlife Diseases, 39, $10-15$.

Daw, C. T., 2011. Mycobacterium paratuberculosis and autism: Is this a trigger? Medical Hypotheses, 77, 977-981.
El-Deeb, W. M., T. A. Fouda \& S. M. ElBahr, 2014. Clinicobiochemical investigations of partuberculosis of camels in Saudi Arabia: Proinflammatory cytokines and oxidative stress markers. Pakistan Veterinary Journal, 34, 484-488.

Ellingson, J. L. E, J. L. Anderson, J. J. Koziczkowski, R. P. Radcliff, S. J. Sloan, S. E. Allen \& N. M.Sullivan, 2005. Detection of viable Mycobacterium avium subsp. paratuberculosis in retail pasteurized whole milk by two culture methods and PCR. Journal of Food Protection, 68, 966-972.

Feller, M., K. Huwiler, R. Stephan, E. Altpeter, A. Shang, H. Furrer, G. E. Pfyffer, T. Jemmi, A. Baumgartner \& M. Egger, 2007. Mycobacterium avium subspecies paratuberculosis and Crohn's disease: A systematic review and meta-analysis. The Lancet. Infectious diseases, 7, 607-613.

Grant, I. R., H. J. Ball \& M. T. Rowe, 2002. Incidence of Mycobacterium paratuberculosis in bulk raw and commercially pasteurized cows' milk from approved dairy processing establishments in the United Kingdom. Applied Environmental Microbiology, 68, 2428-2435.

Kim, J. M., B. K. Ku, H. N. Lee, I. Y. Hwang, Y. B. Jang, J. Kim, B. H. Hyun \& S. C. Jung, 2013. Mycobacterium avium paratuberculosis in wild boars in Korea. Journal of Wildlife Diseases, 49, 413-417.

Kirkwood, C. D., J. Wagner, K. Boniface, J. Vaughan, W. P. Michalski, A. G. CattoSmith \& D. J. Cameron, 2009. Mycobacterium avium subspecies paratuberculosis in children with early-onset Crohn's disease. Inflammatory Bowel Diseases, 15, 16431655.

Palmer Mitchell V., C. S. William, G. C. Jeremy \& R. S. Judith, 2005. Isolation of Mycobacterium avium subsp paratuberculosis (Map) from feral cats on a dairy farm with Map-infected cattle. Journal of Wildlife Diseases, 41, 629-635.

Pavlik, I., A. Horvathova, L. Dvorska, J. Bartl, P. Svastova, R. du Maine \& I. Rychlik, 
1999. Standardisation of restriction fragment length polymorphism analysis for Mycobacterium avium subspecies paratuberculosis. Journal of Microbiological Methods, 38, 155-167.

Salem, M., A. A. Zeid, D. Hassan, A. El-Sayed \& M. Zschoeck, 2005. Studies on Johne's disease in Egyptian cattle. Journal of Veterinary Medicine, 52, 134-137.

Salem, M., 2009. Detection of Mycobacterium avium subspecies paratuberculosis in German dairy herds and comparative molecular characterization. Ph.D. thesis, University of Giessen, Germany.

Salem, M., A. El-Sayed, A. Fayed \& D. G. Abo El-Hassan, 2012. Subclinical infection of paratuberculosis among camels in Egypt. Journal of American Science, 8, 1141-1147

Salem, M., C. Heydel, A. Elsayed, A, Samia, M. Zschöck \& G. Baljer, 2013. Mycobacterium avium subspecies paratuberculosis: An insidious problem for the ruminant industry. Tropical Animal Health and Production, 45, 351-366.

Scanu, A. M., T. J. Bull, S. Cannas, J. D. Sanderson, L. A. Sechi, G. Dettori, S. Zanetti \& J. Hermon-Taylor, 2007. Mycobacterium avium subspecies paratuberculosis infection in cases of irritable bowel syndrome and comparison with Crohn's disease and Johne's disease: Common neural and immune pathogenicities. Journal of Clinical Microbiology, 45, 3883-3890.

Sechi, L. A., A. M. Scanu, P. Molicotti, S. Cannas, M. Mura, G. Dettori, G. Fadda \& S. Zanetti, 2005. Detection and isolation of Mycobacterium avium subspecies paratuberculosis from intestinal mucosal biopsies of patients with and without Crohn's disease in Sardinia. The American Journal of Gastroenterology, 100, 15291536.

Singh, A. V., S. V. Singh, G. K. Makharia, P. K. Singh \& J. S. Sohal, 2008. Presence and characterization of Mycobacterium avium subspecies paratuberculosis from clinical and suspected cases of Crohn's disease and in the healthy human population in India. International Journal of Infectious Diseases, 12, 190-197.

Singh, A. V., S. V. Singh, P. K. Singh, J. S. Sohal \& M. K. Singh, 2011. High prevalence of Mycobacterium avium subspecies paratuberculosis ('Indian bison type') in animal attendants suffering from gastrointestinal complaints who work with goat herds endemic for Johne's disease in India. International Journal of Infectious Diseases, 15, 677-683.

Uzoigwe, J. C., M. L. Khaitsa \& P. S. Gibbs, 2007. Epidemiological evidence for Mycobacterium avium subspecies paratuberculosis as a cause of Crohn's disease. Epidemiology and Infection, 135, 1057-1068.

Wagner, J., W. Sim, R. F. Bishop, A. G. CattoSmith, D. J. Cameron \& C. D. Kirkwood, 2011. Mycobacterium avium subspecies paratuberculosis in children with earlyonset crohn's disease: A longitudinal follow-up study. Inflammatory Bowel Diseases, 17, 1825-1826.

Whittington, R. J., A. F. Hope, D. J. Marshall, C. A. Taragel \& I. Marsh, 2000. Molecular epidemiology of Mycobacterium avium subsp. paratuberculosis: IS900 restriction fragment length polymorphism and IS1311 polymorphism analyses of isolates from animals and a human in Australia. Journal of Clinical Microbiology, 38, 3240-3248.

Paper received 20.02.2017; accepted for publication 05.06.2017

\section{Correspondence:}

Prof. Wael El-Deeb

College of Veterinary Medicine,

King Faisal University, Saudi Arabia

Hufof 31982 P. O. Box 400, Al-Ihsaa

phone: +966 509296154

e-mail: drwaeleldeeb@yahoo.com 